\title{
MRS Grassroots Education Program Seeks To Turn Kids On To Science
}

The 7th grade physical science class cheered as Ian and his skateboard hit the wall. "Harder!" they yelled. After Ian completed a couple more runs into the wall, I took off the dozen or so layers of bubblewrap we had previously wound around him and suggested, "O.K., now let's do the experiment again." The class shouted their approval. Ian wasn't so sure.

"Scientists like to do experiments," I reminded them, "but before they start they always ask what important question?" "Is it safe?" several responded. I was encouraged that this continuing theme from previous visits was becoming ingrained in their minds.

"And what would happen if I ran old Ian into the wall with no padding?" "He'd get busted up for sure!" Rosa replied. "Yeah, yeah!" the rest of the class encouraged, still wanting to continue the action.

"So, in which case would the wall apply a bigger force to Ian's body - with the bubblewrap, or without it?" I asked. A few people shouted out contradictory guesses. Rather than responding, I let them informally debate the issue with one another. Pretty soon those who understood that the force would be larger without the padding had convinced the others, and the class was in agreement.

"And how would the force change as we added more and more layers of bubblewrap?" I asked. "The more bubblewrap, the smaller the force," they reasoned.

Then I questioned, "Suppose we took a videotape of Ian hitting the wall with no bubblewrap and then showed it in slow motion. Would we find that he slowed down suddenly or gradually?" "Suddenly man, like splat!" Juan replied. "Yeah!" everyone laughed.

"But how would that change as we added more and more layers of bubblewrap?" I inquired. After some thought and debate, consensus was reached that he'd slow down increasingly gradually as more padding was added. I summarized these conclusions on the blackboard and we discussed them. Soon the students were verbalizing what they had reasoned through-high forces are associated with sudden changes in speed, and as changes in speed become more gradual the forces decrease-Newton's Second Law for those of you who may have forgotten.

Only after this activity and another one in which we investigated the effect of mass on acceleration and deceleration did I write $\mathrm{F}=$ ma on the board and define the terms. Then, together we did a simplistic calculation of what the force might be on a middle school skier running into a tree and discussed what would happen if someone lying down had that amount of weight placed on top of him/her.

"Ouch! Those kinds of forces would kill you for sure!" Amy volunteered. Everyone agreed.

"So what can we do to keep people from getting killed or seriously injured in things like skiing collisions or automobile accidents?" I asked. "Fix it up so that they slow down more gradually, like with air bags in cars," Nelson responded. "Or put bales of hay in front of ski lift towers," Samantha added.

The Education Exchange highlights the experiences of scientists and engineers with local schools, along with helpful hints and resources for those who would like to become involved in enhancing student understanding and appreciation of science. If you would like to share your own involvement in science education, contact Finley Shapiro, Department of Electrical and Computer Engineering, Drexel University, Philadelphia, PA 19104 U.S.A.

Telephone (215) 895-6749

Fax (215) 895-1695

Email: shapiro@ece.drexel.edu

Now they were ready to see the videotape of how we at Sandia Labs had designed and tested transportation containers for shipping radioactive waste. There were more exclamations and laughter as we watched dramatic footage of a truck running into a concrete bridge abutment at $80 \mathrm{mph}$ and of a diesel locomotive crashing through a flatbed in a simulated grade crossing accident. (Middle schoolers are into destruction.) The tape described how these tests showed that the shockabsorbing materials built into the radioactive waste containers had slowed them down gradually enough so that little damage occurred and they remained leakproof.

"But even more importantly," I explained, "before the tests, Sandia engineers used Newton's Law (and perhaps a few other trivial details) to calculate the forces and damage that would occur during these accidents, similar to the way you and I worked the problem of the skier hitting the tree. During the crash tests, we made careful measurements to see whether these calculations were correct." (Even calculations done by highly skilled scientists and engineers don't always give the right answers, so whenever possible we do experiments to be sure that our calculations are correct.) "In this case, the test results showed that our calculations were right on. Once we knew we could calculate the results accurately, we didn't have to do hundreds of additional, very expensive crash tests for every imaginable type of accident. Instead we were able to use Newton's Law and the computer to calculate the damage that would occur. This paid off in two ways. First, it saved a lot of money, because each real crash destroyed hundreds of thousands of dollars worth of equipment. Second, we were able to investigate many more types of crashes than we could if we had to smash a real truck each time. This helped us be extra sure that the radioactive waste containers would be safe, even in the worst types of accidents."

"So that's the kind of stuff you do at work," said Sergio. "Right," I replied. "Scientists and engineers get to do lots of interesting things like this. And do you know what's kind of funny? When I first was learning about Newton's Law in middle school I couldn't understand why I had to learn stuff like this because I figured I would never use it. Now I'm glad I did. In fact, many of the topics I never thought I'd use when I was first learning them are now the very things that enable me to have a job that's interesting and pays enough so that my family can afford to have a nice house and do fun things. I hate to think of where $I^{\prime} \mathrm{d}$ be today if I had blown off all the things that I thought were boring or that I would never need to know when I was in school."

The bell rang and the kids scrambled out of class. On the way out several asked, "When are you coming back?" Another stopped to tell me about her science fair project. Then I had three whole minutes to unwind and get things reassembled in preparation for the next class. After a whole day of this, I go home tired, but with a substantial sense of satisfaction, and looking forward to my next visit in three weeks.

Nearly 300 technical employees at Sandia National Laboratories are involved in enhancing K-12 science and math education in Albuquerque schools as well as in schools in rural and Indian reservation ar- 
eas of New Mexico. Some employees visit classrooms and interact directly with students. Others help elementary school teachers (many of whom have little background in science) to overcome science phobia, learn the principles and applications of the science topics scheduled for coverage in their classes in upcoming weeks, design interesting hands-on science activities for their classes, set up computers in their classrooms, access the supplies and equipment needed for science experiments, organize and judge science fairs, and do a host of other things in response to teacher-identified needs. Still others participate in evening tutoring programs at area high schools.

Many Sandians work with a particular school (virtually every elementary and middle school in Albuquerque, the nation's 26th largest school district, is included). Some, however, target particular groups which have historically been underrepresented in science, such as women and ethnic minorities. For example, several of the Labs' outreach groups conduct afterschool programs in which minority middle and high school youth not only get involved in hands-on science-related projects, but also form mentoring relationships with positive adult role models who have overcome ethnic and gender stereotyping to become successful participants in the technical community.

Questionnaires given to teachers and students before and after involvement in the Sandia programs show substantial improvements in attitudes toward science. The Sandians also receive frequent notes and comments from students saying things like, "For the first time I learned some science"; "I really liked that skateboard experiment; it helped me understand that equation $(\mathrm{F}=\mathrm{ma})$ "; and very frequently, "How soon can you come back?" Teacher response is also overwhelmingly favorable. One Albuquerque teacher said, "This has been the most valuable support program in my nine years [as a teacher]." Another wrote that the Sandia employee "greatly enhanced our science program. His rapport with our students and ability to demonstrate that science has practical value has stimulated these [students]." With this kind of feedback, it's not surprising that Sandians find their involvement highly satisfying and rewarding.

Sound interesting? Think you might like to be involved? If so, the MRS Grassroots Education Program could be for you. The MRS grassroots education committee aims to help improve precollege science education in the U.S. and increase the technological literacy of the U.S. public. Initially, the committee is working to encourage individuals to participate in "grassroots" enrichment of science education in their local schools.

Examples of grassroots activities that people could implement locally include (1) working with teachers to help them understand science concepts and/or applications; (2) introducing teachers to and helping them access outstanding science education materials; (3) conducting handson science enrichment activities with students; (4) conducting lab/plant tours to illustrate applications of science; (5) organizing, assisting students with, and judging science fairs or other competitions; and (6) tutoring students.

A number of benefits accrue when such grassroots initiatives are carried out effectively. Students and teachers overcome science-phobia and develop increased interest in technology and its influence on society. This paves the way for increased learning, not only of science content, but also of scientific methodology and logical thought processes. In addition, positive impressions of science and scientists are fostered, gender and ethnic stereotypes regarding scientific aptitude can be broken down, and students become aware of technical career opportunities.

The MRS Grassroots Education Program isn't a program, really, it's a movement-a movement of technical professionals dedicated to enriching science education in their local schools. Such movements are al- ready under way in various communities, such as Albuquerque. MRS would like to help more materials researchers become productively involved. Toward this end, the MRS Bulletin will continue to publicize ongoing programs as models of what you can do in your community. In addition, the Ad Hoc MRS Grassroots Education Committee is considering the benefits of having MRS affiliate with Engineers for Education, a group which is coordinating the K-12 outreach efforts of numerous professional societies. Through such affiliations, the committee hopes to provide training on how to interact effectively with schools, teachers, and students. Training materials have already been written, and Engineers for Education is compiling them into a brochure that will be available to interested members of their constituent societies. In addition, Engineers for Education is developing a database to help people network with other technical professionals involved in similar initiatives, and to access outstanding resources that are already available. But you, the members of the scientific community, will be the key players. Only you can make it happen. The MRS Grassroots Education Committee hopes to inspire at least 500 participants by 1995 .

If you're currently involved in K-12 activities or think you might be interested, please circle number 100 on the Reader Service Card to show your interest and to receive additional information. If there is sufficient response, MRS will help provide the training and resources you'll need to become productively involved with your local schools. In addition, watch for more K-12 coverage in the MRS Bulletin and come to the Grassroots Education activities at the upcoming Fall Meeting in Boston. A lot of kids and teachers hope you'll get involved!

KEN ECKELMEYER

Ken Eckelmeyer, education outreach coordinator at Sandia National Laboratories, Albuquerque, New Mexico, is chair of the MRS Ad Hoc Grassroots Education Committee.

\section{The MRS BULLETIN welcomes your opinion on matters of importance to the materials science community. Write to: Letters to the Editor, Materials Research Society, 9800 McKnight Road, Pittsburgh, PA 15237; FAX (412) 367-4373.}

